\title{
The study of distance changes
} between lumbar bi-cortical pedicle screws and anterior large vessels in patients with lumbar spondylolisthesis

\author{
Li Zhao', Chenguang Wan², Shuhong Han ${ }^{3}$, Baofeng $\mathrm{Li}^{4^{*}}$ and Shaoyi Zheng ${ }^{1^{*}}$
}

\begin{abstract}
Objective: This paper was a anatomical radiographic study of distance between lumbar bi-cortical pedicle screws (BPSs) and anterior large vessels (ALVs) in patients with lumbar spondylolisthesis, and to provide clinical basis for evaluating the safety of bi-cortical pedicle screw implantation during lumbar spondylolisthesis.
\end{abstract}

Methods: Complete Computed tomography (CT) data of 104 patients with grade I lumbar spondylolisthesis (L4 52 and L5 52) and 107 non-spondylolisthesis patients (control group) were collected in this study. The distances between lumbar 4,5(L4,5) and sacrum 1(S1) BPSs and ALVs (abdominal aorta, inferior vena cava, left and right common iliac artery, internal and external iliac artery) were respectively measured at different transverse screw angles (TSAs) $\left(\mathrm{L} 4: 5^{\circ}, 10^{\circ} ; \mathrm{L} 5: 10^{\circ}, 15^{\circ} ; \mathrm{S} 1: 0^{\circ}, 5^{\circ}, 10^{\circ}\right)$ and analyzed by SPSS ( $\left.\mathrm{V} 25.0\right)$. There were three types of distances from the anterior vertebral cortex (AVC) to the ALVS ( $D_{\text {AVC-ALV }}$ ): $D_{\text {AVC-ALV }} N, D_{\text {AVC-ALV }} \geq 0.50 \mathrm{~cm}$, and $D_{\text {AVC-ALV }}<0.50 \mathrm{~cm}$; these different distances represented non-contact, distant and close ALV respectively.

Results: We calculated the incidences of screw tip contacting large vessels at different TSAs and provided the appropriate angle of screw implantation. In non-spondylolisthesis group, in $L 4$, the appropriate left TSA was $5^{\circ}$, and the incidence of the close ALV was 4.62\%. In S1, the appropriate left TSA was $0^{\circ}$ and the incidence of the close ALV was $22.4 \%$, while the appropriate right TSA was $10^{\circ}$ and the incidence of the close ALV was $17.8 \%$. In L4 spondylolisthesis group, in L4, the appropriate left TSA was $5^{\circ}$, and the incidence of the close ALV was 3.8\%. In L5 spondylolisthesis group, in S1, the appropriate left TSA was $0^{\circ}$ and the incidence of the close ALV was $19.2 \%$, while the appropriate right TSA was $10^{\circ}$ and the incidence of the close ALV was $21.2 \%$. The use of BPS was not appropriate on the right side of L4 or on the either side of $L 5$ both in spondylolisthesis and control group. In patients with lumbar 4 spondylolisthesis, the incidences of screw tip contacting large vessels were less than the control group in both $L 4$ and 5 . In patients with lumbar 5 spondylolisthesis, the incidences of screw tip contacting large vessels were less than the control group in L5, while there were no significant difference in $\mathrm{S1}$.

\footnotetext{
*Correspondence: niren79817@163.com; zhsy@smu.edu.cn

${ }^{1}$ Department of Cardiovascular surgery, Nanfang Hospital of Southern

Medical University, Guangzhou 510000, Guangdong, China

${ }^{4}$ Department of Orthopedics, General Hospital of Southern Theater

Command of PLA, The first School of Clinical Medicine, Southern Medical

University, Guangzhou 510000, China

Full list of author information is available at the end of the article
}

(c) The Author(s) 2021. Open Access This article is licensed under a Creative Commons Attribution 4.0 International License, which permits use, sharing, adaptation, distribution and reproduction in any medium or format, as long as you give appropriate credit to the original author(s) and the source, provide a link to the Creative Commons licence, and indicate if changes were made. The images or other third party material in this article are included in the article's Creative Commons licence, unless indicated otherwise in a credit line to the material. If material is not included in the article's Creative Commons licence and your intended use is not permitted by statutory regulation or exceeds the permitted use, you will need to obtain permission directly from the copyright holder. To view a copy of this licence, visit http://creativecommons.org/licenses/by/4.0/. The Creative Commons Public Domain Dedication waiver (http://creativeco mmons.org/publicdomain/zero/1.0/) applies to the data made available in this article, unless otherwise stated in a credit line to the data. 
Conclusion: It is very important that considering the anatomical relationship between the AVC and the ALVs while planning BPSs. The use of BPS does not apply to every lumbar vertebra. In patients with lumbar spondylolisthesis and non-spondylolisthesis patients, the incidences of screw tip contacting large vessels are different.

Keywords: Lumbar spondylolisthesis, Bi-cortical pedicle screw, Screw location, Lumbar intervertebral disc, Blood vessels

\section{Background}

Lumbar spondylolisthesis is caused by congenital dysplasia, trauma, strain and other reasons, resulting in the translation of 1 vertebral body over the other and causing instability of the segment [1]. In patients with osteoporosis, due to the poor bone quality, the anti-pullout force of the pedicle screws is significantly inadequate. The screw loosening may lead to operation failure [2].

Traditional methods to improve the stability of pedicle screw are described in detail below:(1) Increased the depth of pedicle screw [3], (2) Using bone cement to strengthen the fixation of pedicle screws [4], (3) Improving the design of pedicle screw, such as expansion screw [5]; First and foremost, Although bone cement augmentation of a pedicle screw is considered a reliable and feasible method up to decreased the incidence of screw loosening, it bears a risk of cement leakage and pulmonary embolism [6]. Secondly, A G Brantley et al. [4] found that screw size had little effect on fixed stiffness in patients with osteoporosis. Third and last, an increase in depth of insertion of the pedicle screw to form a BPS results in higher pullout force and energy [3]. The stress was dispersed between the two cortical bones [7], so that the fixation strength of cortical bone was significantly higher than the cancellous bone. To our knowledge, there were presently little reports on the anatomical structure of ALVs and their association with BPSs.

Therefore, we used imaging methods to study and analyze the lumbar CT images data of patients with lumbar spondylolisthesis and non-spondylolisthesis, and measured the distance between BPSs and ALVs respectively, so as to improve the operation safety and provide anatomical basis.

\section{Materials and methods}

\section{General information}

Inclusion criteria: (1) Patients, who underwent lumbar disc CT scan (L3-S1) in the Affiliated Hospital of Chengde Medical University from April 2018 to September 2020, were included in our analysis; (2) the imaging data were clear and high-quality, and there was no foreign body artifact;

Exclusion criteria: (1) CT image data of non-Affiliated Hospital of Chengde Medical University, with unclear display; (2) patients diagnosed with scoliosis, vertebral fracture, tumor, tuberculosis or transversal vertebrae; (3) patients with lumbar or retroperitoneal surgery history affecting normal anatomy.

\section{Method}

The Meyerding classification grade [8] is determined by measuring the degree of slip. The classification system divides slip into five grades: 0 to $25 \%$ is Grade I, 25 to $50 \%$ is Grade II, 50 to $75 \%$ is Grade III, 75 to $100 \%$ is Grade IV, and greater than $100 \%$ is Grade V. This article selects patients with grade I slippage in L4 and L5.

Xinru Du et al. $[9,10]$ found that when the L4 TSA is $5-10^{\circ}$, the L5 TSA is $10-15^{\circ}$ and the S1 TSA is $0-10^{\circ}$, the pedicle screw passes through the central axis of the pedicle, which is the connecting line between the screw placement point and the midpoint of the pedicle stenosis at different TSAs. According to the author's suggestion, we assumed the pedicle screw is on the central axis of the pedicle and respectively measured the distances between BPSs in L4,5 and S1 and ALVs at different TSAs $\left(\mathrm{L} 4: 5^{\circ}, 10^{\circ} ; \mathrm{L} 5: 10^{\circ}, 15^{\circ} ; \mathrm{S} 1: 0^{\circ}, 5^{\circ}, 10^{\circ}\right)$ (Fig. 1). According to the $\mathrm{D}_{\text {AVC-ALV }}$ different [11], the distance between AVC and ALV was classified into three types: non-contact, distant and close ALVs. If the prolonged line segment of the BPS did not contact the ALV, it was indicated as " $D_{\text {AVC- }}$ ALV N" which meant a non-contact ALV. If the prolonged line segment of the BPS contacted the ALV and the distance was larger or equal to $0.50 \mathrm{~cm}$, it was indicated as " $D_{\text {AVC-ALV }} \geq 0.50 \mathrm{~cm}$ " which meant a distant ALV. If the prolonged line segment of the BPS contacted the ALV and the distance was less than $0.50 \mathrm{~cm}$, it was expressed as " $\mathrm{D}_{\text {AVC-ALV }}<0.50 \mathrm{~cm}$ " which meant a close ALV. Then, we calculated the incidences of these three types of ALV at each TSA of the BPSs in L4, L5 and S1. The higher the incidence of the close ALV, the higher the risk of injury potential to the ALV. We also collected the participants' age and sex.

\section{Statistical data processing}

The measurement data were expressed as mean \pm standard deviation and t-test was adopted. We use $x^{2}$ test to test the counting data. With SPSS (V25.0) for statistical analysis, when the $p$-value less than $0.05(p<0.05)$, the difference was statistically significant. 


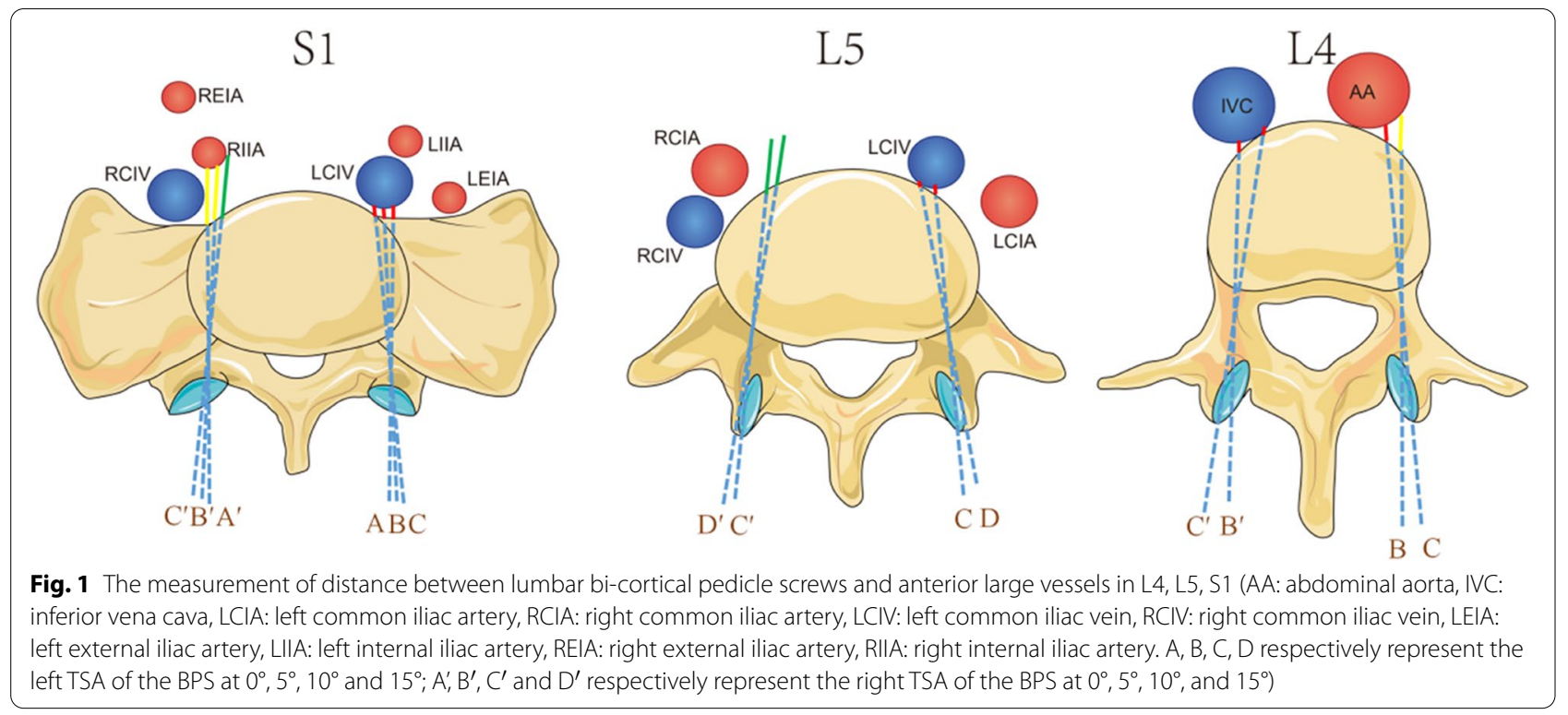

\section{Results}

\section{General information of research objects}

In this study, 104 cases of lumbar spondylolisthesis (L4 52 cases, L5 52 cases), including 27 males and 77 females. There were 107 cases in the control group, including 38 males and 69 females. There was no significant difference in gender composition between the two groups $\left(\chi^{2}=2.258, p=0.133>0.05\right)$. (Table 1$)$.

\section{Comparison of the distance between BPSs and ALVs in both the control group and spondylolisthesis group}

In the control group, in L4, the incidences of $\mathrm{D}_{\mathrm{AVC}-\mathrm{ALV}}$ $\mathrm{N}, \mathrm{D}_{\mathrm{AVC}-\mathrm{ALV}} \geq 0.50 \mathrm{~cm}$, and $\mathrm{D}_{\mathrm{AVC}-\mathrm{ALV}}<0.50 \mathrm{~cm}$ between the left and right sides were significant difference at $5^{\circ}$ and $10^{\circ}$ respectively $(p<0.05)$. The lowest incidence of the close ALVs on the left side of L4 was $9.3 \%$ at $5^{\circ}$, while the right side was $73.8 \%$ at $10^{\circ}$. In L5, the incidences of $\mathrm{D}_{\text {AVC-ALV }} \mathrm{N}, \mathrm{D}_{\text {AVC-ALV }} \geq 0.50 \mathrm{~cm}$, and $\mathrm{D}_{\text {AVC-ALV }}<0.50 \mathrm{~cm}$ between the left and right sides were not significant difference at and $10^{\circ}$ and $15^{\circ}$ respectively $(p>0.05)$. The lowest incidence of the close ALVs on the left side of L5 was $75.7 \%$ at $10^{\circ}$, while the right side was $73.8 \%$ at $10^{\circ}$. In

Table 1 sex composition and age distribution of subjects

\begin{tabular}{lllll}
\hline Group & Total & Male & Female & Age (years) \\
\hline Spondylolisthesis group & 104 & 27 & 77 & $60.13 \pm 11.305$ \\
Control group & 107 & 38 & 69 & $30.32 \pm 9.031^{(1)}$ \\
\hline
\end{tabular}

Note: (1) compared with spondylolisthesis group, $P<0.05$
S1, the incidences of $\mathrm{D}_{\mathrm{AVC}-\mathrm{ALV}} \mathrm{N}, \mathrm{D}_{\mathrm{AVC}-\mathrm{ALV}} \geq 0.50 \mathrm{~cm}$, and $\mathrm{D}_{\mathrm{AVC}-\mathrm{ALV}}<0.50 \mathrm{~cm}$ between the left and right sides were significant difference at $5^{\circ}$ and $10^{\circ}$ respectively $(p<0.05)$. But there were not significant difference at $0^{\circ}(p>0.05)$. The lowest incidence of the close ALVs on the left side of S1 was $22.4 \%$ at $0^{\circ}$, while the right side was $17.8 \%$ at $10^{\circ}$.

In the L4 spondylolisthesis group, in L4, the incidences of $D_{\text {AVC-ALV }} \quad \mathrm{N}, \quad D_{\text {AVC-ALV }} \geq 0.50 \mathrm{~cm}$, and $\mathrm{D}_{\text {AVC-ALV }}<0.50 \mathrm{~cm}$ between the left and right sides were significant difference at $5^{\circ}$ and $10^{\circ}$ respectively $(p<0.05)$. The lowest incidence of the close ALVs on the left side of $\mathrm{L} 4$ was $3.8 \%$ at $5^{\circ}$, while the right side was $36.5 \%$ at $10^{\circ}$. In L5, the incidences of $\mathrm{D}_{\text {AVC-ALV }} \mathrm{N}$, $\mathrm{D}_{\text {AVC-ALV }} \geq 0.50 \mathrm{~cm}$, and $\mathrm{D}_{\text {AVC-ALV }}<0.50 \mathrm{~cm}$ between the left and right sides were not significant difference at $10^{\circ}$ and $15^{\circ}$ respectively $(p>0.05)$. The lowest incidence of the close ALVs on the left side of L5 was $53.8 \%$ at $10^{\circ}$, while the right side was $46.2 \%$ at $10^{\circ}$.

In the L5 spondylolisthesis group, in L5, the incidences of $\mathrm{D}_{\mathrm{AVC}-\mathrm{ALV}} \mathrm{N}, \mathrm{D}_{\mathrm{AVC}-\mathrm{ALV}} \geq 0.50 \mathrm{~cm}$, and $\mathrm{D}_{\text {AVC-ALV }}<0.50 \mathrm{~cm}$ between the left and right sides were not significant difference at $10^{\circ}$ and $15^{\circ}$ respectively $(p>0.05)$. The lowest incidence of the close ALVs on the left side of L5 was $50 \%$ at $10^{\circ}$, while the right side was $51.9 \%$ at $15^{\circ}$. In $\mathrm{S} 1$, the incidences of $\mathrm{D}_{\text {AVC-ALV }} \mathrm{N}$, $\mathrm{D}_{\text {AVC-ALV }} \geq 0.50 \mathrm{~cm}$, and $\mathrm{D}_{\text {AVC-ALV }}<0.50 \mathrm{~cm}$ between the left and right sides were significant difference at $5^{\circ}$ and $10^{\circ}$ respectively $(p<0.05)$. But there were not significant difference at $0^{\circ}(p>0.05)$. The lowest incidence of the close ALVs on the left side of S1 was $19.2 \%$ at $0^{\circ}$, while the right side was $21.2 \%$ at $0^{\circ}$ and $10^{\circ}$. (Table 2). 
Table 2 Comparison of the distance between BPSs and ALVs in both the control group and spondylolisthesis group

\begin{tabular}{|c|c|c|c|c|c|c|c|c|}
\hline Lumbar & TSA & Type & Left Number (\%) & Right Number (\%) & $P_{1}$ & Left $D_{\text {AVC-ALV }}(\mathrm{cm})$ & Right $D_{\text {AVC-ALV }}(\mathrm{cm})$ & $P_{2}$ \\
\hline \multicolumn{9}{|c|}{ Control group } \\
\hline \multirow[t]{3}{*}{ L4 } & 5 & $\mathrm{~N}$ & $58(54.2 \%)$ & $2(1.9 \%)$ & & & & \\
\hline & & $\geq$ & $39(36.4 \%)$ & $14(13.1 \%)$ & 0.000 & $0.99 \pm 0.13$ & $0.57 \pm 0.03$ & 0.000 \\
\hline & & $<$ & 10 (9.3\%) & $91(85 \%)$ & & $0.33 \pm 0.07$ & $0.28 \pm 0.07$ & 0.013 \\
\hline \multirow[t]{3}{*}{$\llcorner 4$} & 10 & $\mathrm{~N}$ & $16(15 \%)$ & $4(3.7 \%)$ & & & & \\
\hline & & $\geq$ & 60 (56.1\%) & $24(22.4 \%)$ & 0.000 & $0.78 \pm 0.08$ & $0.66 \pm 0.07$ & 0.000 \\
\hline & & $<$ & $31(29 \%)$ & 79 (73.8\%) & & $0.31 \pm 0.04$ & $0.16 \pm 0.06$ & 0.000 \\
\hline \multirow[t]{3}{*}{ L5 } & 10 & $\mathrm{~N}$ & $8(7.5 \%)$ & $11(10.3 \%)$ & & & & \\
\hline & & $\geq$ & $18(16.8 \%)$ & $17(15.9 \%)$ & 0.768 & $0.7 \pm 0.05$ & $0.58 \pm 0.03$ & 0.000 \\
\hline & & $<$ & $81(75.7 \%)$ & 79 (73.8\%) & & $0.11 \pm 0.04$ & $0.07 \pm 0.06$ & 0.000 \\
\hline \multirow[t]{3}{*}{ L5 } & 15 & $\mathrm{~N}$ & $5(4.7 \%)$ & $15(14 \%)$ & & & & \\
\hline & & $\geq$ & $4(3.7 \%)$ & $4(3.7 \%)$ & 0.063 & $0.68 \pm 0.03$ & $0.61 \pm 0.029$ & 0.073 \\
\hline & & $<$ & $98(91.6 \%)$ & $88(82.2 \%)$ & & $0.12 \pm 0.05$ & $0.12 \pm 0.05$ & 0.749 \\
\hline \multirow[t]{3}{*}{ S1 } & 0 & N & $21(19.6 \%)$ & $20(18.7 \%)$ & & & & \\
\hline & & $\geq$ & $62(57.9 \%)$ & 65 (60.7\%) & 0.913 & $0.95 \pm 0.22$ & $0.75 \pm 0.07$ & 0.000 \\
\hline & & $<$ & $24(22.4 \%)$ & $22(20.6 \%)$ & & $0.21 \pm 0.1$ & $0.31 \pm 0.07$ & 0.000 \\
\hline \multirow[t]{3}{*}{ S1 } & 5 & $\mathrm{~N}$ & $18(16.8 \%)$ & $29(27.1 \%)$ & & & & \\
\hline & & $\geq$ & $11(10.3 \%)$ & $46(43 \%)$ & 0.000 & $1.04 \pm 0.1$ & $0.79 \pm 0.11$ & 0.000 \\
\hline & & $<$ & 78 (72.9\%) & 32 (29.9\%) & & $0.26 \pm 0.08$ & $0.24 \pm 0.06$ & 0.353 \\
\hline \multirow[t]{3}{*}{ S1 } & 10 & $\mathrm{~N}$ & $40(37.4 \%)$ & $87(81.3 \%)$ & & & & \\
\hline & & $\geq$ & $11(10.3 \%)$ & $1(0.9 \%)$ & 0.000 & $1.03 \pm 0.09$ & 0.5 & 0.000 \\
\hline & & $<$ & $56(52.3)$ & $19(17.8 \%)$ & & $0.18 \pm 0.09$ & $0.39 \pm 0.04$ & 0.000 \\
\hline \multicolumn{9}{|c|}{ L4 spondylolisthesis group } \\
\hline \multirow[t]{3}{*}{ L4 } & 5 & N & 42 (80.8\%) & $12(23.1 \%)$ & & & & \\
\hline & & $\geq$ & $8(15.4 \%)$ & $19(36.5 \%)$ & 0.000 & $1.24 \pm 0.05$ & $0.73 \pm 0.06$ & 0.000 \\
\hline & & $<$ & $2(3.8 \%)$ & $21(40.4 \%)$ & & $0.39 \pm 0.03$ & $0.42 \pm 0.04$ & 0.365 \\
\hline \multirow[t]{3}{*}{ L4 } & 10 & $\mathrm{~N}$ & $17(32.7 \%)$ & $8(15.4 \%)$ & & & & \\
\hline & & $\geq$ & $27(51.9 \%)$ & $19(36.5 \%)$ & 0.001 & $0.88 \pm 0.1$ & $0.78 \pm 0.06$ & 0.000 \\
\hline & & $<$ & $8(15.4 \%)$ & $25(48.1 \%)$ & & $0.43 \pm 0.04$ & $0.39 \pm 0.04$ & 0.021 \\
\hline \multirow[t]{3}{*}{ L5 } & 10 & $\mathrm{~N}$ & $8(15.4 \%)$ & $12(23.1 \%)$ & & & & \\
\hline & & $\geq$ & $16(30.8 \%)$ & $16(30.8 \%)$ & 0.575 & $0.76 \pm 0.05$ & $0.75 \pm 0.07$ & 0.742 \\
\hline & & $<$ & $28(53.8 \%)$ & $24(46.2 \%)$ & & $0.2 \pm 0.05$ & $0.15 \pm 0.05$ & 0.001 \\
\hline \multirow[t]{3}{*}{ L5 } & 15 & N & $9(17.3 \%)$ & $15(28.8 \%)$ & & & & \\
\hline & & $\geq$ & $8(15.4 \%)$ & $8(15.4 \%)$ & 0.357 & $0.8 \pm 0.05$ & $0.7 \pm 0.05$ & 0.012 \\
\hline & & $<$ & $35(67.3 \%)$ & $29(55.8 \%)$ & & $0.22 \pm 0.07$ & $0.19 \pm 0.06$ & 0.043 \\
\hline \multicolumn{9}{|c|}{ L5 spondylolisthesis group } \\
\hline \multirow[t]{3}{*}{ L5 } & 10 & N & $10(19.2 \%)$ & $8(15.4 \%)$ & & & & \\
\hline & & $\geq$ & $16(30.8 \%)$ & $13(25 \%)$ & 0.54 & $0.79 \pm 0.07$ & $0.71 \pm 0.06$ & 0.001 \\
\hline & & $<$ & $26(50 \%)$ & $31(59.6 \%)$ & & $0.24 \pm 0.05$ & $0.17 \pm 0.05$ & 0.000 \\
\hline \multirow[t]{3}{*}{ L5 } & 15 & N & $9(17.3 \%)$ & $17(32.7 \%)$ & & & & \\
\hline & & $\geq$ & $9(17.3 \%)$ & $8(15.4 \%)$ & 0.088 & $0.83 \pm 0.08$ & $0.78 \pm 0.07$ & 0.259 \\
\hline & & $<$ & $34(65.4 \%)$ & $27(51.9 \%)$ & & $0.26 \pm 0.08$ & $0.23 \pm 0.06$ & 0.1 \\
\hline \multirow[t]{3}{*}{ S1 } & 0 & N & $11(21.2 \%)$ & $11(21.2 \%)$ & & & & \\
\hline & & $\geq$ & $31(59.6 \%)$ & $30(57.7 \%)$ & 0.969 & $0.99 \pm 0.07$ & $0.7 \pm 0.04$ & 0.000 \\
\hline & & $<$ & 10 (19.2\%) & $11(21.2 \%)$ & & $0.2 \pm 0.23$ & $0.29 \pm 0.04$ & 0.000 \\
\hline \multirow[t]{3}{*}{ S1 } & 5 & N & $10(19.2 \%)$ & $14(26.9 \%)$ & & & & \\
\hline & & $\geq$ & $6(11.5 \%)$ & $24(46.2 \%)$ & 0.000 & $0.91 \pm 0.03$ & $0.82 \pm 0.06$ & 0.001 \\
\hline & & $<$ & $36(69.2 \%)$ & $14(26.9 \%)$ & & $0.21 \pm 0.07$ & $0.2 \pm 0.06$ & 0.784 \\
\hline \multirow[t]{3}{*}{ S1 } & 10 & $\mathrm{~N}$ & $21(40.4 \%)$ & $41(78.8 \%)$ & & & & \\
\hline & & $\geq$ & $5(9.6 \%)$ & 0 & 0.000 & $1 \pm 0.05$ & & \\
\hline & & $<$ & $26(50 \%)$ & $11(21.2 \%)$ & & $0.13 \pm 0.07$ & $0.41 \pm 0.04$ & 0.000 \\
\hline
\end{tabular}

Note: $\mathrm{N}_{1} \geq$ and $<$ represented non-contact, distant and close ALV respectively 


\section{Effect of lumbar spondylolisthesis on the distance between BPSs and ALVs in L4, L5 and S1}

In the L4 spondylolisthesis group, in L4, the incidences of $\mathrm{D}_{\text {AVC-ALV }} \mathrm{N}, \mathrm{D}_{\mathrm{AVC}-\mathrm{ALV}} \geq 0.50 \mathrm{~cm}$, and $\mathrm{D}_{\mathrm{AVC}-\mathrm{ALV}}<0.50 \mathrm{~cm}$ between the spondylolisthesis and control group were significant difference at $5^{\circ}$ and $10^{\circ}$ respectively $(p<0.05)$. In L5, the incidences of $\mathrm{D}_{\mathrm{AVC}-\mathrm{ALV}} \mathrm{N}, \mathrm{D}_{\mathrm{AVC}-\mathrm{ALV}} \geq 0.50 \mathrm{~cm}$, and $\mathrm{D}_{\mathrm{AVC}-\mathrm{ALV}}<0.50 \mathrm{~cm}$ between the spondylolisthesis and control group were significant difference at $10^{\circ}$ and $15^{\circ}$ respectively $(p<0.05)$ (Table 3$)$.

In the $\mathrm{L} 5$ spondylolisthesis group, in $\mathrm{L} 5$, the incidences of $\mathrm{D}_{\text {AVC-ALV }} \mathrm{N}, \mathrm{D}_{\mathrm{AVC}-\mathrm{ALV}} \geq 0.50 \mathrm{~cm}$, and $\mathrm{D}_{\text {AVC-ALV }}<0.50 \mathrm{~cm}$ between the spondylolisthesis and control group were significant difference at $10^{\circ}$ and $15^{\circ}$ respectively $(p<0.05)$. In $S 1$, the incidences of $D_{\text {AVC-ALV }} \mathrm{N}, \mathrm{D}_{\mathrm{AVC}-\mathrm{ALV}} \geq 0.50 \mathrm{~cm}$, and $\mathrm{D}_{\mathrm{AVC}-\mathrm{ALV}}<0.50 \mathrm{~cm}$ between the spondylolisthesis and control group were not significant difference at $0^{\circ}, 10^{\circ}$ and $15^{\circ}$ respectively $(p>0.05)$ (Table 4$)$.

Based on the above results, we found that in patients with lumbar 4 spondylolisthesis, the incidences of screw tip contacting large vessels were less than the control group in both L4 and 5, and in patients with lumbar 5 spondylolisthesis, the incidences of screw tip contacting large vessels were less than the control group in L5, while there were no significant difference in S1.

\section{Discussion}

The BPS insertion method was initially used for S1 [12]. In this text, the authors clarify the safety scope of BPSs. In recent years, there are numerous clinical studies that have confirmed the feasibility and mechanical advantages of BPSs [13-15]. In 2015, Le Cann et al. [7] through using pig lumbar spine concluded that the pedicle screw fixation device needs to be bi-cortical to enhance stability in young animals. In the same year, Karami et al. [3] through osteoporotic cadaveric lumbar spines concluded that additional purchase of the stiff anterior cortex is indispensable for achieving superior screw-bone structure stability and rigidity. The advantages of BPS fixation were confirmed by animal experiments and cadaveric experiments. Thus, we measured the distance between BPSs and ALVs in order to reduce the incidence of vascular injury.

Shinya Okuda et al. $[16,17]$ reported that complications associated with pedicle screws misplacement. The intraoperative Complications they reported were dural tearing, pedicle screw malposition and nerve injury. The early postoperative complications they reported were pulmonary, cardiac, and cerebrovascular morbidity, hardware failure, infection and neurological complications. The late postoperative complications they reported were hardware failure, nonunion, late infection, and adjacent-segment degeneration. To improve the accuracy of pedicle screw placement and to reduce the complications associated with pedicle screws misplacement, we can use imaging-guided navigation.

Imaging-guided navigation can provide the surgeon with additional anatomical information to increase precision of setting pilot holes for pedicle screws [18]. In a meta-analysis for placement of pedicle screws in the spine, image-guided navigation showed a higher accuracy 95.5\% compared with $91.5 \%$ for freehand placement [19]. Previous studies have summarized several approaches of image-guided navigation, which included fluoroscopyassisted, computed tomography image navigation, and robot-assisted [20]. In 2019, through retrospective analysis of the 51,161 pedicle screw cases, Alexander Perdomo-Pantoja et al. [21] concluded that the CT provides the highest pedicle screw placement accuracy and lowest rates of revision, compared with other techniques of image-guided navigation.

Placing BPSs precisely is essential to bi-cortical fixation, as protruding screw tips can damage ALVs [13, 22]. In order to place BPSs precisely, the depth and angle of screw must be planned before operation. Previous studies $[23,24]$ indicate that the safe distance rage of the BPSs protruding tips should be maintained within the $5 \mathrm{~mm}$. This is essential for the secure use of BPSs to improve the strength of fixation. Our finding suggests that in non-spondylolisthesis group, the appropriate left TSA was $5^{\circ}$ in L4, the appropriate left TSA was $0^{\circ}$ in S1, and the appropriate right TSA was $10^{\circ}$ in S1. In patients with lumbar 4 spondylolisthesis, the appropriate left TSA was $5^{\circ}$ in L4. In patients with lumbar 5 spondylolisthesis, the appropriate left TSA was $0^{\circ}$ in $\mathrm{S} 1$ and the appropriate right TSA was $10^{\circ}$ in S1. However, The BPSs insertion method were not suitable for every lumbar spine. The use of BPS was not appropriate on the right side of L4 or on the either side of L5, which is similar with the finding result of Liehua Liu et al. [11]. In addition, the author also concluded the recommended TSA of each BPS of L1-L3. Meanwhile, we also find that in patients with lumbar 4 spondylolisthesis, the incidences of screw tip contacting large vessels were less than the control group in both L4 and 5 and in patients with lumbar 5 spondylolisthesis, the incidences of screw tip contacting large vessels were less than the control group in L5, while there were no significant difference in S1. The reasons are as follows: Patients with lumbar spondylolisthesis often occur labial hyperosteogeny on the upper and lower margin of the vertebral body, and the hyperplastic osteophytes push the anterior longitudinal ligament and large vessels forward, thus increasing the distance between BPSs and ALVs [25], while, at the level of L5-S1 intervertebral disc, the abdominal aorta 


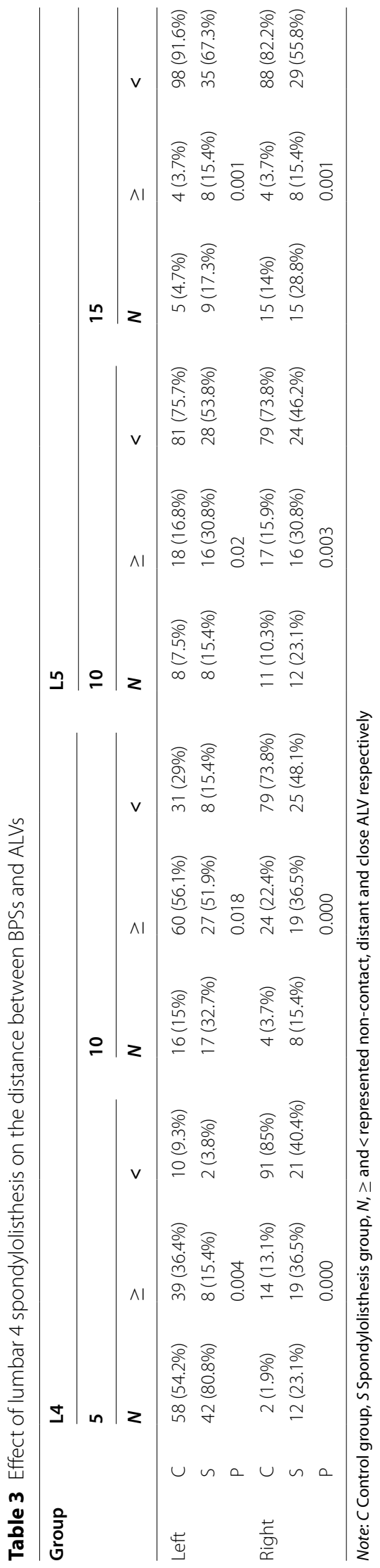




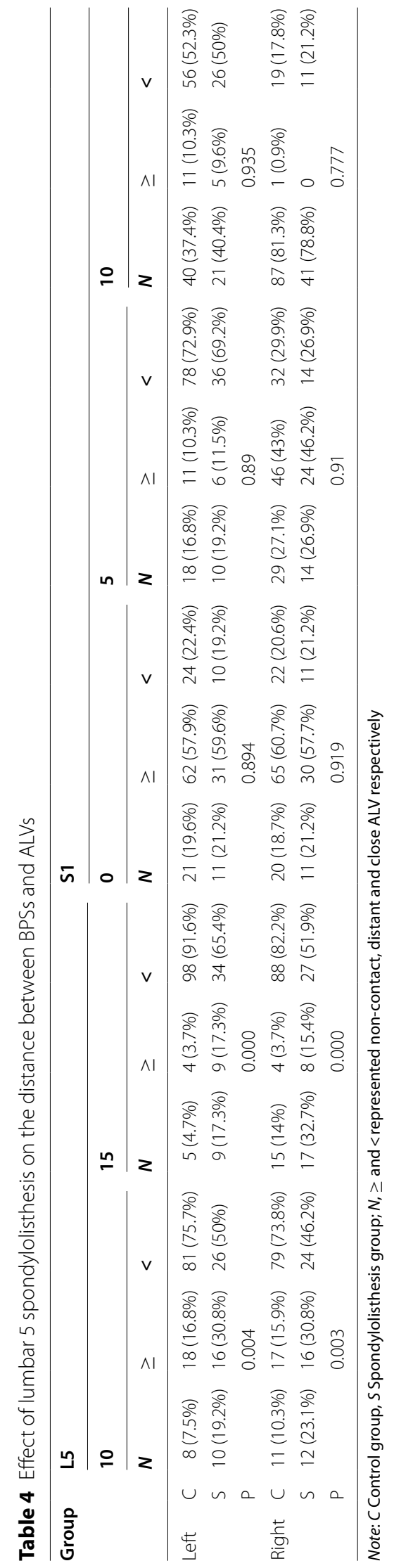


and inferior vena cava have bifurcated into the left and right common iliac arteries and veins, and some patients have even bifurcated into internal and external iliac arteries and veins, and for these patients, the operative window of intervertebral disc surgery has a large range [26], and the hyperplastic osteophytes may avoid the large vessels. Thus, we think that in S1, there were no significant difference in the incidences of large vessels between spondylolisthesis and non-spondylolisthesis group.

Luis Marchi et al. [22] summarize different factors which may affect the closest distance between the lumbar spine and anterior large vessels. One of them is lumbar lordosis. The author's results show that lordosis did not significantly affect the closest distance between the lumbar spine and anterior large vessels at any level. The reasons may be as follows: when the lumbar lordosis increases, the abdominal aorta and inferior vena cava will also produce physiological lordosis, but the relative position with the lumbar vertebral body remains unchanged.

In order to avoid damage to the ALVs, we suggest that each surgeon must make his own surgical strategy, with due consideration of preoperative imaging examination. First and foremost, the BPS insertion method suggested in this research can not completely prevent damage to the ALV. Secondly, if necessary, patient should undergo a computed tomography angiography (CTA) examination before operation, which can be used to identify the angle and depth of the BPS. Third and last, it can be considered safe when the protruding tip of the pedicle screws to be less than $3 \mathrm{~mm}$ [23].

There are several limitations in our study. Firstly, there are inevitable measurement in the experimental data, and the clinical effect not studied. Secondly, The CT images used as a reference for placing BPSs are taken commonly when the patient is supine position, while the traditional operative position is prone. In order to the effect of body positions on the distance between BPSs and ALVs, Riccio A et al. [27] through experiments found that the inferior vena cava and the abdominal aorta in the lumbar region is relatively immobile in the prone and supine positions. Thus, we believe that the distance between BPSs and ALVs has no significant difference in different body positions. Future studies can investigate the relative distance between BPSs and the ALVs in different body positions.

To sum up, the use of BPS does not apply to every lumbar vertebra. When placing BPSs, we present the appropriate TSAs in L4 and S1. In patients with lumbar spondylolisthesis and non-spondylolisthesis patients, the incidences of screw tip contacting large vessels are different.

\section{Abbreviations}

BPSs: Bi-cortical pedicle screws; ALVs: Anterior large vessels; CT: Computed tomography; AVC: Anterior vertebral cortex; CTA: Computed tomography angiography.

\section{Acknowledgements}

We would like to thank all the reviewers for the careful evaluation of the manuscript and appreciate the reviewers' insightful comments and suggestions which can help to improve our work.

\section{Authors' contributions}

LBF and ZSY designed the study. ZL wrote the main manuscript text. LBF and ZSY revised manuscript. WCG and HSH analyzed the data. The author(s) read and approved the final manuscript.

\section{Funding}

Not applicable.

\section{Availability of data and materials}

The datasets used and/or analyzed during the current study are available from the corresponding author on reasonable request. Readers can access the data and material supporting the conclusions of the study by contacting Li Zhao at 654720450@qq.com.

\section{Declarations}

\section{Ethics approval and consent to participate}

The present study was approved by the Ethics Committee of the Nanfang Hospital of Southern Medical University. Informed consent obtained from each participant was written. All protocols are carried out in accordance with relevant guidelines and regulations.

\section{Consent for publication}

Not applicable.

\section{Competing interests}

The authors declare that they have no conflict of interest.

\section{Author details}

${ }^{1}$ Department of Cardiovascular surgery, Nanfang Hospital of Southern Medical University, Guangzhou 510000, Guangdong, China. ${ }^{2}$ Department of Neurosurgery, Tianjin First Central Hospital, Tianjin 300000, China. ${ }^{3}$ Department of Spine Surgery, Affiliated Hospital of Chengde Medical College, Chengde 067000, Hebei, China. ${ }^{4}$ Department of Orthopedics, General Hospital of Southern Theater Command of PLA, The first School of Clinical Medicine, Southern Medical University, Guangzhou 510000, China.

Received: 29 July 2021 Accepted: 22 October 2021

Published online: 01 November 2021

\section{References}

1. Bydon M, Alvi M, Goyal A. Degenerative lumbar Spondylolisthesis: definition, natural history, conservative management, and surgical treatment. Neurosurg Clin N Am. 2019;30(3):299-304.

2. Liu Y, Xiao J, Yin X, Liu M, Zhao J, Liu P, et al. Clinical efficacy of bone cement-injectable Cannulated pedicle screw short segment fixation for lumbar Spondylolisthesis with Osteoporosise. Sci Rep. 2020;10(1):3929.

3. Karami K, Buckenmeyer L, Kiapour A, Kelkar P, Goel V, Demetropoulos $\mathrm{C}$, et al. Biomechanical evaluation of the pedicle screw insertion depth effect on screw stability under cyclic loading and subsequent pullout. J Spinal Disord Tech. 2015;28(3):133-9.

4. Weiser L, Sellenschloh K, Püschel K, Morlock M, Viezens L, Lehmann W, et al. Reduced cement volume does not affect screw stability in augmented pedicle screws. Eur Spine J. 2020;29(6):1297-303.

5. Gazzeri R, Roperto R, Fiore C. Surgical treatment of degenerative and traumatic spinal diseases with expandable screws in patients 
with osteoporosis: 2-year follow-up clinical study. J Neurosurg Spine. 2016;25(5):610-9.

6. Janssen I, Ryang Y, Gempt J, Bette S, Gerhardt J, Kirschke J, et al. Risk of cement leakage and pulmonary embolism by bone cementaugmented pedicle screw fixation of the thoracolumbar spine. Spine J. 2017;17(6):837-44.

7. Le Cann S, Cachon T, Viguier E, Miladi L, Odent T, Rossi J, et al. Pedicle screw fixation study in immature porcine spines to improve pullout resistance during animal testing. PLoS One. 2015:10(10):0127463.

8. Koslosky E, Gendelberg D. Classification in brief: the Meyerding classification system of Spondylolisthesis. Clin Orthop Relat Res. 2020;478(5):1125-230.

9. Xinru $D$, Yimo Z, Lingxiu Z, et al. Radiological anatomical study of accuracy entrance point for the placement of pedicle screw through posterior approach. J Bone Joint Injury. 2000;15(3):206-8

10. Lingxiu Z, Xinru D, Kong X. Applied anatomy of the structures around sacrum and its relevancies. Chin J Clin Anatomy. 2004;22(2):139-42.

11. Liu L, Wang H, Wang J, Wang Q, Cheng S, Li Y, et al. The methods for inserting lumbar bicortical pedicle screws from the anatomical perspective of the prevertebral great vessels. BMC Musculoskelet Disord. 2019;20(1):380.

12. Mirkovic S, Abitbol JJ, Steinman J, Edwards CC, Schaffler M, Massie $J$, et al. Anatomic consideration for sacral screw placement. Spine. 1991;16(6):289-94.

13. Kato M, Taneichi H, Suda K. Advantage of pedicle screw placement into the sacral promontory (Tricortical purchase) on lumbosacral fixation. J Spinal Disord Tech. 2015;28(6):336-42.

14. Zhu Q, Lu WW, Holmes AD, Zheng Y, Zhong S, Leong JC. The effects of cyclic loading on pull-out strength of sacral screw fixation: an in vitro biomechanical study. Spine. 2000;25(9):1065-9.

15. Kim YY, Ha KY, Kim SI, Oh IS. A study of sacral anthropometry to determine $\mathrm{S} 1$ screw placement for spinal lumbosacral fixation in the Korean population. Eur Spine J. 2015;24(11):2525-9.

16. Jutte P, Castelein R. Complications of pedicle screws in lumbar and lumbosacral fusions in 105 consecutive primary operations. Eur Spine J. 2002;11(6):594-8.

17. Okuda S, Miyauchi A, Oda T, Haku T, Yamamoto T, Iwasaki M. Surgical complications of posterior lumbar interbody fusion with total facetectomy in 251 patients. J Neurosurg Spine. 2006;4(4):304-9.
18. Dennler C, Jaberg L, Spirig J, Agten C, Götschi T, Fürnstahl P, et al. Augmented reality-based navigation increases precision of pedicle screw insertion. J Orthop Surg Res. 2020;15(1):174.

19. Kosmopoulos V, Schizas C. Pedicle screw placement accuracy: a metaanalysis. Spine. 2007;32(3):111-20.

20. Puvanesarajah V, Liauw J, Lo S, Lina I, Witham T. Techniques and accuracy of thoracolumbar pedicle screw placement. World J Orthop. 2014;5(2):112-23.

21. Perdomo-Pantoja A, Ishida W, Zygourakis C, Holmes C, Iyer R, Cottrill E, et al. Accuracy of current techniques for placement of pedicle screws in the spine: a comprehensive systematic review and Meta-analysis of 51,161 screws. World Neurosurg. 2019;126:664-78.

22. Park Y, Hyun S, Choi H, Kim K, Jahng T. Association between bicortical screw fixation at upper instrumented vertebra and risk for upper instrumented vertebra fracture. J Neurosurg Spine. 2017;26(5):638-44.

23. Xu C, Hou Q, Chu Y, Huang X, Yang W, Ma J, et al. How to improve the safety of bicortical pedicle screw insertion in the thoracolumbar vertebrae: analysis base on three-dimensional CT reconstruction of patients in the prone position. BMC Musculoskelet Disord. 2020;21(1):444.

24. Di Silvestre M, Parisini P, Lolli F, Bakaloudis G. Complications of thoracic pedicle screws in scoliosis treatment. Spine. 2007;32(15):1655-61.

25. Xinyu C. The study in imaginativeanatomy of pre-nail site of pedicle screw and the distance change of the great vessels in front of Lumbar with bone hyperplasia: Yanbian University; 2012. p. 2012.

26. Guohua L, Wang BIN, Feiwen L. An experimental study of operative approach of laparoscopic lumbar spine surgery. Chin J Spine Spinal Cord. 2003;13(9):558-61.

27. Riccio A, Bishop A, Carl A. Great vessel excursion: prone versus supine position. Int J Spine Surg. 2019;13(2):158-61.

\section{Publisher's Note}

Springer Nature remains neutral with regard to jurisdictional claims in published maps and institutional affiliations.
Ready to submit your research? Choose BMC and benefit from:

- fast, convenient online submission

- thorough peer review by experienced researchers in your field

- rapid publication on acceptance

- support for research data, including large and complex data types

- gold Open Access which fosters wider collaboration and increased citations

- maximum visibility for your research: over $100 \mathrm{M}$ website views per year

At BMC, research is always in progress.

Learn more biomedcentral.com/submissions 